\title{
Impactos socioambientais na Amazônia Oriental: um olhar a partir da atividade siderúrgica na comunidade Piquiá de Baixo - Açailândia (MA)
}

\section{Socio-environmental impacts in the eastern amazon: a look at steelmaking activity in the Piquiá de Baixo community - Açailândia (MA)}

\section{Impactos socioambientales en la amazonía oriental: una mirada a la actividad siderúrgica en la comunidad de Piquiá de Baixo - Açailândia (MA)}

\footnotetext{
1 Mestrando do Programa de Pós-Graduação em Geografia (PPGG) - Universidade Federal do Tocantins (UFT) - Brasil luucas.ribeiros@hotmail.com
}

\section{Resumo}

Este trabalho aborda a questão do desenvolvimento econômico, buscando enfatizar a implantação de grandes projetos na Amazônia Oriental, em especial, os empreendimentos siderúrgicos, além disso, retrata os impactos decorrentes de tais iniciativas. Dessa forma, o objetivo central deste estudo é analisar o processo de implantação de siderúrgicas na cidade de Açailândia - MA e as consequências não só ambientais, como também sociais, culturais e territoriais que acabam por afetar diretamente as populações adjacentes, em especial a comunidade Piquiá de Baixo. Por se tratar de uma pesquisa de cunho qualitativo, adotou-se como estratégias metodológicas, a pesquisa bibliográfica, além da observação simples e a análise de dados levantados junto à comunidade.

Palavras-chave: Impactos socioambientais. Siderurgias. Piquiá (MA)

\begin{abstract}
This paper addresses the issue of economic development, seeking to emphasize the implementation of large projects in the Eastern Amazon, especially steel enterprises, and also portrays the impacts resulting from such initiatives. Thus, the central objective of this study is to analyze the process of implementing steel mills in the city of Açailândia - MA and the consequences not only environmental, but also social, cultural and territorial that end up directly affecting the adjacent populations, especially the Piquiá de Baixo community. Since this is a qualitative research, it was adopted as methodological strategies, the bibliographical research, in addition to simple observation and analysis of data collected from the community.
\end{abstract}

Keywords: Socioenvironmental impacts. Siderurgies. Piquiá (MA).

\section{Resumen}


Este documento aborda el tema del desarrollo económico, buscando enfatizar la implementación de grandes proyectos en la Amazonía Oriental, especialmente las empresas siderúrgicas, y también retrata los impactos que resultan de tales iniciativas. Por lo tanto, el objetivo central de este estudio es analizar el proceso de implementación de acerías en la ciudad de Açailândia - MA y las consecuencias no sólo ambientales, sino también sociales, culturales y territoriales que terminan afectando directamente a las poblaciones adyacentes, especialmente a la comunidad de Piquiá de Baixo. Al tratarse de una investigación cualitativa, se adoptó como estrategias metodológicas la investigación bibliográfica, además de la simple observación y análisis de los datos recogidos en la comunidad.

Palabras clave: Impactos socioambientales. Acerías. Piquiá (MA).

\section{Introdução}

A palavra siderurgia, deriva da junção dos vocábulos gregos sideros, que quer dizer ferro, e ergon, que significa trabalho. O trabalho com o ferro, sempre esteve ligado as conquistas do homem. E o Brasil, por ter o maior parque industrial de aço da América do Sul, acaba se destacando nesse cenário, ficando no ranking dos países que mais produzem aço no mundo.

A atividade siderúrgica, historicamente, vem ocupando um papel de destaque no âmbito da economia brasileira. A siderurgia foi e continua sendo uma indústria essencial para o Brasil, na medida em que é o alicerce de várias cadeias produtivas, tais como a automotiva, a da construção civil, a de bens de capital, dentre outras.

No entanto, tais atividades, vem ocasionando diversos impactos a população e ao meio ambiente, que vão desde a falta de preocupação com a sustentabilidade; o desrespeito aos modos de vida dos povos e comunidades tradicionais e a destruição do bioma para exploração das riquezas do subsolo ou para a produção de carvão vegetal.

Nessa perspectiva, o presente artigo surge em razão das reflexões realizadas na Universidade Estadual do Maranhão - UEMA, durante a graduação em Geografia, em especial nas aulas de Geopolítica, Geografia Regional e Geografia Agrária, que consequentemente trouxeram alguns questionamentos em torno dos impactos gerados por grandes empreendimentos a comunidades adjacentes. 
Nesse sentido, o presente artigo busca compreender os efeitos socioambientais decorrentes da atividade siderúrgica na comunidade Piquiá de Baixo - Açailândia/MA; bem como, conhecer os fatores que concorreram para a implantação de tais empreendimentos e entender o posicionamento dos moradores da comunidade diante dos impactos gerados pela siderurgia.

\section{Caminho Metodológico}

Compreendemos que a metodologia nos estudos de natureza científica se apoia na adoção por parte do pesquisador, de métodos de abordagem, utilizando-se teorias reconhecidas num dado campo do conhecimento, bem como métodos científicos e técnicas de pesquisa que lhe são inerentes.

Nesses termos, cumpre destacar que o presente artigo prezou pela utilização da abordagem qualitativa. Segundo Gil (2008, p.21) “A pesquisa qualitativa responde a questões muito particulares. Ela se preocupa [...] com um nível de realidade que não pode ser quantificado". A mesma é de suma importância nos estudos socioambientais, a medida com maior profundidade a compreensão do contexto da situação, considerando o universo de significados, aspirações, crenças, valores e atitudes impregnados nos fatos.

Ao considerar estes aspectos, a presente pesquisa se concentrou em três momentos: O primeiro foi a pesquisa bibliográfica, com o intuito de compor um quadro teórico atual e pertinente a respeito da Amazônia Oriental e dos impactos ocasionados por grandes projetos econômicos, amparada principalmente nas contribuições de Becker (1982, 2003, 2005), Pestana (2013), Rocha (2015), Santos (2004) e Sousa (2009).

O segundo foi a observação simples, na qual Gil (2008) define como "aquela em que o pesquisador, permanecendo alheio à comunidade, grupo ou situação que pretende estudar, observa de maneira espontânea os fatos que aí ocorrem”. Esta etapa promoveu o envolvimento com os moradores da comunidade, em especial, os mais antigos. $\mathrm{O}$ contato foi realizado em uma praça, na qual os mesmos relataram suas indignações com relação ao empreendimento supracitado e os impactos causados pelo mesmo.

E por último, a análise de dados levantados. Onde foi possível fazer uma relação dos dados secundários, que são as assertivas dos autores e demais fontes utilizadas na 
fundamentação deste artigo, com os dados primários, que foram as informações coletadas juntamente com a comunidade.

Estes instrumentos metodológicos foram essenciais para o processo de desenvolvimento desta investigação, pois forneceram as direções adequadas para a compreensão das particularidades das atividades siderúrgicas e seus reflexos em níveis: sociais, ambientais, culturais e territoriais.

\section{Um breve histórico do processo de ocupação da região amazônica}

Desde a década de 1950, a Amazônia brasileira vem sofrendo grandes mudanças em seu cenário socioespacial. Estas mudanças foram acarretadas em razão de vários investimentos estruturais através da adoção de projetos e programas governamentais, realizados pelos governos militares, com o objetivo de viabilizar o desenvolvimento desta região.

Nesse sentido, era necessário a inserção da Amazônia no processo de ocupação e povoamento, visto que o Brasil passava por um estreito vínculo com o sistema capitalista global.

Algumas ferrovias e rodovias tais como a Belém-Brasília e a Transamazônica foram implantadas. As que já existiam foram recuperadas. Portos foram construídos nas principais cidades litorâneas, com a finalidade de escoar a produção para o comércio nacional e internacional. Conforme Becker (2005):

[...] É a partir de 1960 que se inicia o processo de urbanização regional, a princípio com a construção da rodovia Belém-Brasília e, a seguir com a política territorial do Estado, a "política de integração nacional", que intensificou os fluxos de mercadorias (bens e serviços), energia (trabalho, imigração, dinheiro) e informação (inovações e comunicações e envolveu uma política urbana e migratória [...] (BECKER, 2005, p. 405).

Com a implantação desses grandes projetos econômicos, o êxodo rural passou a vigorar nessa área. Pois uma considerável quantidade de camponeses que se encontravam sem trabalho, passou a buscar as cidades para residirem e assim, desenvolverem alguma atividade econômica, fato marcante no processo de urbanização do Brasil. De acordo com Santos (2004): 
[...] Efetivamente, nas condições atuais da divisão internacional do trabalho, a industrialização nem sempre é capaz de criar um "crescimento" com "desenvolvimento", mas apenas um "pseudodesenvolvimento", devido à ausência de articulação local das atividades e da distribuição regressiva da renda [...] (SANTOS, 2004, p. 31).

Até meados da década de 1960 a urbanização na Amazônia estava organizada por meio de uma rede dendrítica, obedecendo ao ritmo das redes fluviais, ou seja, as populações em sua maioria residiam às margens dos rios, fato que mudou a partir de 1960 quando se inicia a construção das rodovias federais. Nessa direção, Sousa (2009) enfatiza:

[...] o processo recente de ocupação da Amazônia [...] caracterizado pela atuação conjunta do capital e do estado que, agindo conjuntamente subsidiaram direta/indiretamente a ocupação da região através de projetos de natureza diversificada. Suas ações se voltaram para a construção de rodovias, a implantação dos projetos de colonização e a instauração de programas agropecuários e mineradores. (SOUSA, 2009, p. 57).

A organização hierárquica das cidades foi alterada após 1950. Tal alteração se fez a partir do duplo movimento de concentração/desconcentração, que Becker (2005) define:

[...] O movimento de concentração corresponde ao padrão histórico primaz de crescimento das duas grandes capitais regionais, agora, porém, com a reprodução desse padrão em capitais estaduais que continuamente crescem, ascendendo a classes de tamanho superiores. [...] a desconcentração refere-se ao crescimento de núcleos que não constituem capitais. (BECKER, 2005, p. 406).

Esse processo de desconcentração tanto econômico, quanto populacional, fez com que ocorresse uma redução da participação das grandes cidades, o que permitiu o crescimento de médias e pequenas cidades, promovendo uma reestruturação urbana e regional. Conforme Becker (2005) comenta:

A outra face da desconcentração é constituída pela multiplicação dos médios e pequenos núcleos de $<10.000$ e de $10-<50.000$, os quais, em conjunto, constituem a maioria dos núcleos regionais, que correspondem a um padrão móvel e instável de urbanização. (BECKER, 2005, p. 407). 
Outro fator determinante para a intensificação da ocupação da Amazônia brasileira é o fato de ser considerada uma região com grande valor econômico, o que facilitaria a reprodução do capital. Sobre estes aspectos, Becker (1982) fala:

As fronteiras de recursos são definidas como zonas de povoamento novo, em que o território virgem é ocupado e tornado produtivo. [...] Em virtude do alto valor de seus recursos naturais e do seu despovoamento, esta região é capaz de absorver inovações e atrair efeitos de difusão do crescimento. Constitui-se, assim, como uma fronteira de recursos, ou seja, uma região de novas oportunidades. (BECKER, 1982, p. 650).

Isso fez com que, as terras amazônicas que em sua grande maioria não tinham nenhum tipo de produção, passassem a se tornar produtivas, dando início aos vários modos de exploração dos recursos naturais. Conforme Becker (2005) destaca:

[...] sua ocupação se fez em surtos devassadores desencadeados pela valorização momentânea de produtos no mercado externo. Em meados da década de 1960, é o estado brasileiro que toma a si o comando de um novo ciclo de povoamento regional no contexto de um projeto geopolítico para a modernização acelerada da sociedade e do território brasileiro. [...] (BECKER, 2005, p. 401).

Esta interação com o mundo capitalista permitiu que a região da Amazônia vivenciasse grandes mudanças estruturais, ocasionadas pelo acelerado surgimento de inovações, havendo uma maior conectividade entre os lugares, ou seja, localidades que antes tinham difícil acesso, com a instauração da política de modernização passaram a encurtar os limites de distâncias, acarretando num processo mais intenso de fluxo de pessoas, de mercadorias e serviços.

As ações políticas e econômicas se efetivaram através da adoção de diferentes programas e projetos instaurados e desenvolvidos entre as décadas de 1960-1980. Assim sendo, o Estado transferiu à iniciativa privada o gerenciamento e a organização do processo de ocupação e povoamento regional.

Ao considerar estas transformações socioespaciais ocorridas na Amazônia brasileira a partir de 1950 é que situamos as particularidades destas mudanças na comunidade Piquiá de Baixo, que está localizada no município de Açailândia, que é parte integrante da Amazônia Oriental e que conheceu de perto as transformações acarretadas pela atividade siderúrgica, não somente em nível ambiental, como também, social, territorial e cultural. 


\title{
Localização e Caracterização da Área de Estudo
}

A comunidade Piquiá de Baixo fica situada no município de Açailândia, que está localizado na região sudoeste do estado do Maranhão. Atualmente, a presente cidade conta com 111.757 habitantes, segundo estimativas do Instituto Brasileiro de Geografia e Estatística - IBGE (2018).

Açailândia está situada entre os limites de duas grandes rodovias, a BR-010 e a BR-222. Também se cruzam no limite desta cidade duas importantes ferrovias, a estrada de Ferro Carajás e a Ferrovia Norte-Sul, que acabaram por se tornar eixos favorecedores da implantação de grandes empreendimentos voltados não somente para a siderurgia, como também para o extrativismo vegetal.

Açailândia foi emancipada no dia 6 de junho de 1981, conforme Lei Estadual 4.295/81 e Lei Orgânica de Açailândia/1990. De acordo com dados do (IBGE), a cidade possui área territorial de $5.806,440 \mathrm{~km}^{2}$; densidade demográfica de $17,92 \mathrm{hab} / \mathrm{km}^{2}$. O PIB per capita é de $\mathrm{R} \$ 16.929,09$. O seu IDH é de 0, 672. Sua atual conjuntura econômica está diretamente ligada a projetos desenvolvimentistas. Conforme falam Sousa; Vacovski; Soares (2017):

\begin{abstract}
A formação e ocupação das terras do município de Açailândia data dentre os anos de 1958 e 1960 e está atrelada e vinculada aos projetos governamentais da União de ocupação populacional e posterior exploração econômica da Amazônia Oriental Brasileira e interligação rodo-ferroviária dessa e demais regiões à recente capital Brasília, com a construção da BR 010 Belém-Brasília, autorizada pelo então presidente Juscelino Kubitschek através de decreto $\mathrm{n}^{\circ} 43.909$. (SOUSA; VACOVSKI; SOARES, 2017, 07).
\end{abstract}

É nesse sentido que a comunidade Piquiá de Baixo acaba sofrendo diretamente com os impactos socioambientais oriundos de tais iniciativas desenvolvimentistas, já que se encontra localizada às margens da BR-222, conforme podemos observar no mapa a seguir: 
Mapa 1 - Complexo Siderurgico em Acailândia - Maranhão

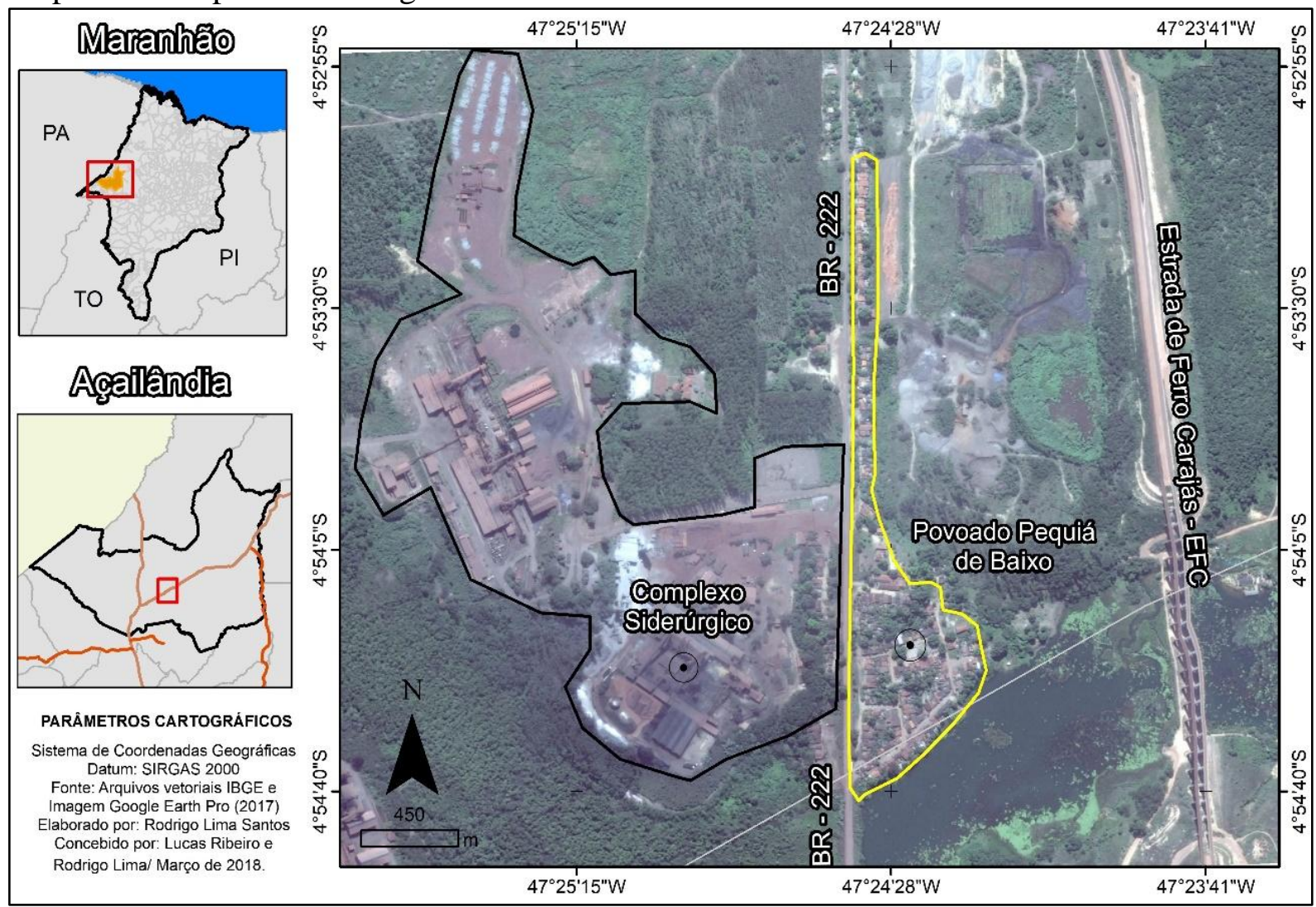

Fonte: Santos \& Silva (2018)

Além disso, outros fatores propiciaram a implantação de um polo industrial nos limites de tal comunidade, como a presença do Rio Cajuapara e das madeireiras, que acabam por contribuir na produção de carvão vegetal, utilizado nos fornos para a produção do ferro-gusa. Nessa direção, Rocha (2015) fala:

A região passou a concentrar os investimentos mínero-metalúrgicos do município, por assumir alguns condicionamentos necessários à implantação dos projetos como: água advinda do Rio Cajuapara; nas proximidades da Estrada de Ferro Carajás, com uma distância de 2 km da área das empresas, facilitando assim embarques e desembarques de minérios e produtos siderúrgicos; madeireiras instaladas na margem da rodovia BR-222, que produziam carvão vegetal, matéria-prima essencial à produção do ferro-gusa e mão de obra em abundância, principalmente dos agricultores que ali já residiam. (ROCHA, 2015, p. 6)

Segundo dados de Vieira (2010) é no fim dos anos de 1970 que se inicia o desenvolvimento do Bairro Piquiá de Baixo. Primeiramente com o intuito de abrigar famílias oriundas de outras cidades que se direcionavam até essa localidade para trabalhar nas empreiteiras construtoras da BR-222. 
Em seguida, com a saída das empreiteiras, após a construção da BR-222, camponeses de diversos estados do Brasil, passam a fixar-se nessas terras, acreditando que as mesmas fossem devolutas e com a esperança de terem naquele "pedaço de chão" uma vida melhor.

No entanto, cabe salientar que mesmo com o término da BR-222, outros empreendimentos continuaram a funcionar nas proximidades, como as madeireiras e outras prestadoras de serviços. Mas foi no início dos anos 1980, que esta área ganha visibilidade novamente, tendo em vista, os investimentos oriundos da implantação do Programa Grande Carajás. De acordo com Pestana (2013):

O Programa Grande Carajás contribuiu decisivamente para a implantação do polo siderúrgico em Açailândia, na medida em que a extração de minério em grande escala para abastecimento da demanda internacional, importou na construção da EFC que conectou o sítio de extração na Serra dos Carajás, localizada no estado do Pará, até o Porto da Ponta da Madeira em São Luís/MA. (PESTANA, 2013, p. 34-35).

Assim, foi nesse contexto que o núcleo da comunidade Piquiá de Baixo teve seus moldes iniciais, sendo marcada pelo contraste entre as práticas de diversas atividades econômicas, como já foram citados anteriormente, e o cotidiano de famílias simples, praticantes de tarefas vinculadas ao campo. E é nesse sentido, que o próximo item deste trabalho aborda os impactos socioambientais que acabam por acontecer, tendo em vista esta relação de não complementariedade.

\section{A Atividade Siderúrgica e os Impactos Socioambientais na Comunidade Piquiá de Baixo - Açailândia/MA}

Para que se fosse possível realizar uma melhor analise do problema em questão, houve a necessidade de se utilizar a técnica da observação simples, que em conjunto com os relatos que foram cedidos pelos moradores, nos mostraram que a comunidade Piquiá de Baixo vivencia diversos problemas acarretados pela atividade siderúrgica, que não são somente de cunho ambiental, mas também, sociais, culturais e territoriais. Nesse sentido, o presente item deste trabalho, busca de forma sucinta evidenciar alguns desses descasos.

Para o seu funcionamento, deve-se levar em consideração o resfriamento dos altos-fornos presentes nas siderúrgicas, nesse sentido as mesmas utilizam a água do Rio 
Impactos socioambientais na Amazônia Oriental: um olhar a partir da atividade siderúrgica na comunidade Piquiá de Baixo - Açailândia (MA)

SILVA, L. R. da

Piquiá dos Baianos, que consequentemente, retorna superaquecida e com resíduos de metais, deixando-a imprópria para uso da população, que muitas das vezes a utilizava em seus afazeres domésticos, bem como prática de lazer.

Além disso, é disperso no ar uma fumaça tóxica e preta, composta de resíduos de carvão, ferro, entre outros metais, que é uma das responsáveis pelos diversos problemas de saúde vivenciados pela comunidade, conforme podemos observar nas imagens a seguir:

Foto 1 - Atividade siderúrgica na comunidade Piquiá de Baixo - MA

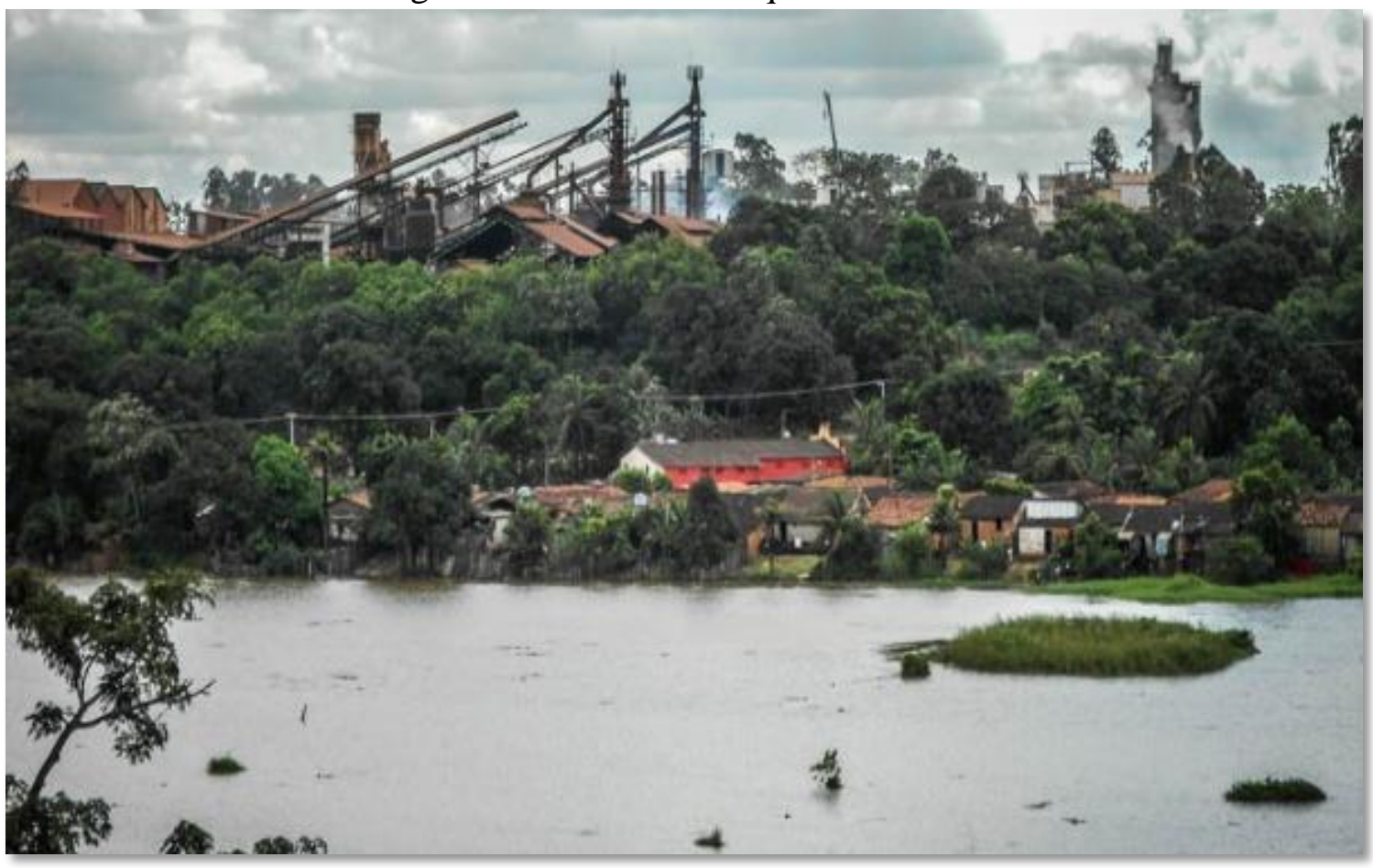

Fonte: Rede Justiça nos Trilhos, 2016.

Essa fumaça acaba por invadir as residências dos moradores, desencadeando uma série de doenças respiratórias, dentre outros problemas. Conforme salienta Rocha; Silva; Loiola:

Observa-se diariamente nas residências deste bairro, resíduos oriundos do trabalho desenvolvido pelas indústrias com grande contaminação de pó químico agravando a saúde de seus moradores sendo recorrentes doenças de pele e respiratórias. As patologias englobam problemas respiratórios, tanto agudos quanto crônicos, além de doenças de pele, alta incidência de câncer na população, problemas digestivos, problemas oftalmológicos, abortos, problemas cardíacos e outros. Diversos laudos técnicos constataram que a convivência entre as 
indústrias e os assentamentos humanos na localidade é inviável. (ROCHA; SILVA; LOIOLA, 2015, p. 10).

Além disso, no processo de queima do carvão vegetal é produzido um rejeito denominado munha, que ainda incandescente, é disperso sobre os terrenos próximos às residências da comunidade sem nenhuma proteção e que queima durante vários dias, onde segundo os moradores, muitas crianças e animais já se acidentaram, sofrendo graves queimaduras.

Os moradores da comunidade vivem no esquecimento do poder público. O saneamento básico é precário, a coleta de lixo é realizada uma vez por semana e a população que já sofre cotidianamente com a emissão de gases poluentes e barulhos ensurdecedores, tenham que conviver com a falta de tratamento dos resíduos domésticos.

A educação é deficitária, já que a comunidade detém de apenas uma escola, o que inviabiliza um ensino de qualidade, fazendo com que muitas crianças e adolescentes que sonham com um futuro melhor, se desloquem $16 \mathrm{~km}$ todos os dias para estudarem em escolas localizadas no perímetro urbano de Açailândia.

A renda das famílias é baseada no cultivo e criação de animais de subsistência, trabalhos assalariados ou os famosos bicos, recebimento de auxílios oriundos de programas sociais, tal como o Bolsa Família e de aposentadorias ou pensões previdenciárias. Mas há também quem realize trabalhos nas próprias siderúrgicas, sendo uma parcela pequena da comunidade.

Com a presença da BR-222, na qual há a transitação de diversos veículos, outros problemas de cunho social surgem, tais como a prostituição de crianças e adolescentes, a venda e consumo de drogas, além do trabalho escravo.

E foi nesse sentido de insatisfação vivenciada por toda população, que a associação de moradores, juntamente com entidades, tais como igrejas e o a Rede Justiça nos Trilhos, travaram diversas lutas em prol do reassentamento das famílias. Os tramites de reassentamento poderiam ter sido mais ágeis, se não fosse a resistência das empresas em reconhecer sua responsabilidade e em contribuir na composição dos recursos para o projeto do novo bairro.

Tudo isso obrigou os moradores a pleitearem, por meio de sua associação, recursos públicos do Programa Minha Casa Minha Vida. Conforme destaca a Rede Justiça nos Trilhos (2018): 
Entre 2007 e 2012, a luta da comunidade foi para formar uma mesa de negociação onde estivessem presentes as siderúrgicas, o Município e o Estado. Alguns acordos foram firmados. Só em 2013 a Associação teve condições técnicas e financeiras de apresentar o projeto para aprovação na prefeitura local. Em 2014 o projeto básico foi apresentado e aprovado pela Caixa Econômica Federal e em 2015 foi selecionado pelo Ministério das Cidades, o que garantiu cerca de $60 \%$ dos recursos (públicos) necessários à construção do novo bairro. $\mathrm{O}$ terreno para o reassentamento foi obtido após uma longa batalha em ação judicial de desapropriação, concluída em 2015. O novo espaço terá que receber toda a infraestrutura a que as famílias têm direito e serão necessários $\mathrm{R} \$ 29$ milhões, sendo que desse montante apenas $\mathrm{R}$ \$ 2 milhões e 130 mil (7,5\%) foram aportados pelas empresas siderúrgicas. (REDE JUSTIÇA NOS TRILHOS, 2018, n. p).

A área destinada ao reassentamento da comunidade, também fica as margens da BR-222, conhecida anteriormente por Sítio São José. Até o final do ano de 2018, as obras estavam na fase de limpeza do terreno, para assim prosseguir com a fase de construção das casas populares. Diante das lutas realizadas pela comunidade, em busca de sua qualidade de vida e dignidade, os moradores em votação decidiram dar um novo nome ao seu bairro, que passa a denominar-se Piquiá da Conquista.

\section{Considerações Finais}

Com o presente trabalho consideramos que os grandes projetos econômicos são em grande parte responsáveis pelos impactos socioambientais decorrentes nas áreas onde se instalam. E no caso específico do município de Açailândia - MA, tais impactos são sentidos na pele por toda a população da comunidade Piquiá de Baixo.

Ao se instalar, esses grandes projetos econômicos lançam seus discursos desenvolvimentistas e de progresso, no sentido de acalmarem a população e fazer com que o empreendimento seja aceito por todos. Entretanto, tais atitudes não passam de mera formalidade.

Como foi observado durante a fase de observação simples deste estudo, a população sofre com problemas de cunho social, cultural, territorial e principalmente ambiental. Nota-se que um empreendimento dessa magnitude traz consigo grandes expectativas para a população de seu entorno, porém, os mesmos acabam por se frustrar, tendo em vista os diversos impactos gerados. 
Há a possibilidade de a legislação ambiental estar sendo infringido na localidade, por parte das siderúrgicas, o que exige um acompanhamento recorrente por parte dos órgãos ambientais responsáveis, no que diz respeito ao monitoramento e fiscalização, para assim criar medidas preventivas e que gerem punições cabíveis.

\section{Referências}

BECKER, B. K. Geopolítica da Amazônia: a nova fronteira de recursos. Rio de Janeiro, 1982.

BECKER, B. K. Dinâmica urbana na Amazônia. In: Clécio Campolina Diniz, Mauro Borges Lemos. Economia e território. Belo Horizonte: Editora UFMG, 2005, p. 401-428.

GIL, Antônio Carlos. Métodos e técnicas de pesquisa social. 1ed. - 17 reimpr. São Paulo: Atlas, 2008.

GUERRA, E. L. A. Manual de pesquisa qualitativa. Belo Horizonte: Anima Educação, 2014.

INSTITUTO BRASILEIRO DE GEOGRAFIA E ESTATÍSTICA. Informações estatísticas sobre o município de Açailândia/MA. Disponível em: http://www.ibge.gov.br/home/. Acesso em: 11 de fevereiro de 2019.

MINAYO, M. C. S. (Org.). Pesquisa social: teoria, método e criatividade. Petrópolis: Vozes, 2009.

PESTANA, T. V. Os impactos socioambientais decorrentes da atividade siderúrgica na comunidade Pequiá de Baixo em Açailândia/MA. (Dissertação de Mestrado em Meio Ambiente e Desenvolvimento). Centro universitário Univates, 2013. $133 p$.

REDE JUSTIÇA NOS TRILHOS. Piquiá de Baixo luta há 10 anos por reassentamento longe da poluição. Disponível em: http://justicanostrilhos.org/2018/01/22/piquia-debaixo-luta-ha-10-anos-por-reassentamento-longe-da-poluicao. Acesso em: $18 \mathrm{fev}$. 2019.

ROCHA, M. R. V. S; SILVA, D. C. O; LOIOLA, E. AMAZÔNIA ORIENTAL: impactos socioambientais em Pequiá de Baixo no Município de Açailândia-MA. Acta ambiental catarinense, v. 12, n. 1/2, p. 1-14, 2015.

SOUSA, J. M. Aspectos históricos da urbanização de Imperatriz. In: A cidade na região e a região na cidade: a dinâmica socioeconômica de Imperatriz e suas implicações na região Tocantina. Imperatriz, MA: Ética, 2009. 
Impactos socioambientais na Amazônia Oriental: um olhar a partir da atividade siderúrgica na comunidade Piquiá de Baixo - Açailândia (MA)

SILVA, L. R. da

SOUSA, F. C; VACOVSKI, E; SOARES, F. S. PEQUIÁ DA CONQUISTA: a vitória dos de baixo contra os gigantes de ferro. Observatório, v. 3, n. 2, p. 417-453, 2017.

VIEIRA, S. Açailândia, eixo do Maranhão Imperatriz: Ética Editora, 2010. Disponível em: <www.justi_canostrilhos.org>. Acesso em: 15 abril. 2018. 